\title{
Distal Tibial Stress Fracture Secondary to Severe Osteoarthritis Knee
}

\author{
Raviraj Adala, Surendranath Shetty, Ashish Anand", Rajendran Ravidnran \\ Department of Orthopedic Surgery, Fortis Hospitals Ltd., Bangalore, India \\ Email: *ashishanandortho@yahoo.com
}

Received December 12, 2012; revised January 15, 2013; accepted January 23, 2013

Copyright (C) 2013 Raviraj Adala et al. This is an open access article distributed under the Creative Commons Attribution License, which permits unrestricted use, distribution, and reproduction in any medium, provided the original work is properly cited.

\begin{abstract}
Stress fractures of the tibia are commonly seen in young athletes or military recruits due to repetitive micro trauma. These are rare in elderly patients. Osteoarthritis knee with varus deformity leading to stress fracture is rare, but it has been reported in literature. Stress fracture in osteoarthritis more commonly occurs in upper third tibia. We report a patient who had stress fractures of distal tibial shaft secondary to advanced osteoarthritis of knee with varus deformity.
\end{abstract}

Keywords: Fracture; Stress; Fractures; Tibia; Osteoarthritis; Knee; Tibia

\section{Introduction}

Stress fractures occur due to repetitive cumulative micro trauma on the bone over a period of time. They occur either due to abnormal stress placed on a normal bone (fatigue fracture) or normal stress placed on an abnormal bone (insufficiency fracture). The commonest site of affection is the tibia in up to $50 \%$ cases. Tibial stress fractures are often seen in military recruits and athletic trainees $[1,2]$. In elderly people stress fractures are much less common, but they have been reported in association with osteoporosis, rheumatoid arthritis and pyrophosphate arthropathy of the knee [3-7]. The stress fracture occurring in elderly patients due to severe osteoarthritis and varus deformity is rare. And the very few cases reported in English literature, the site involved is upper third of the tibia [8-15]. We report a patient who had stress fractures of distal tibial shaft secondary to advanced osteoarthritis of knee with varus deformity.

\section{Case Report}

A 65-year old patient reported to Joint Replacement and adult reconstruction services of our department with history of increased pain in the knee associated with difficulty in walking and climbing the stairs for the past seven years. She had been advised knee replacement 2 years back in another centre. The radiographs of the knee at that time showed severe osteoarthritis knee (Figure 1) with varus deformity. She also gave the history of in

${ }^{*}$ Corresponding author. creased pain in the lower leg region and the $\mathrm{x}$ rays of the leg were unremarkable and patient was advised Total Knee Arthroplasty (TKA) for both the knee to relieve pain and improve function. Patient denied surgery and was put on oral medications for the leg pain and was advised to come for a TKA once the acute pain subsided. Patient did not have any other medical illness, was not on any medications and was a non smoker.

Patient followed up 8 months later with deformity of the lower third of the leg and inability to bear weight and walk for the past three weeks. She was treated elsewhere by immobilization for six months for a stress fracture lower third tibia. The radiograph showed stress fracture distal tibia with angulation and deformity (Figure 2). There was sclerosis at the ends of the bone and gap at the fracture site.

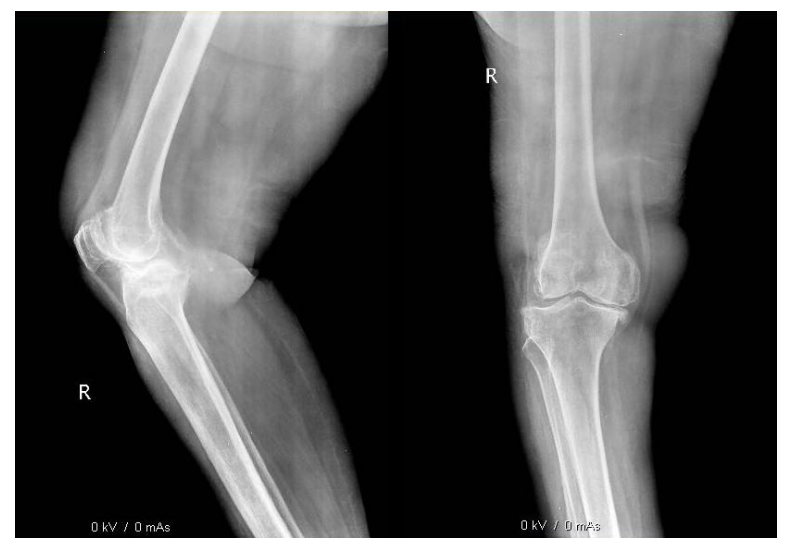

Figure 1. Severe osteoarthritis knee with varus deformity. 


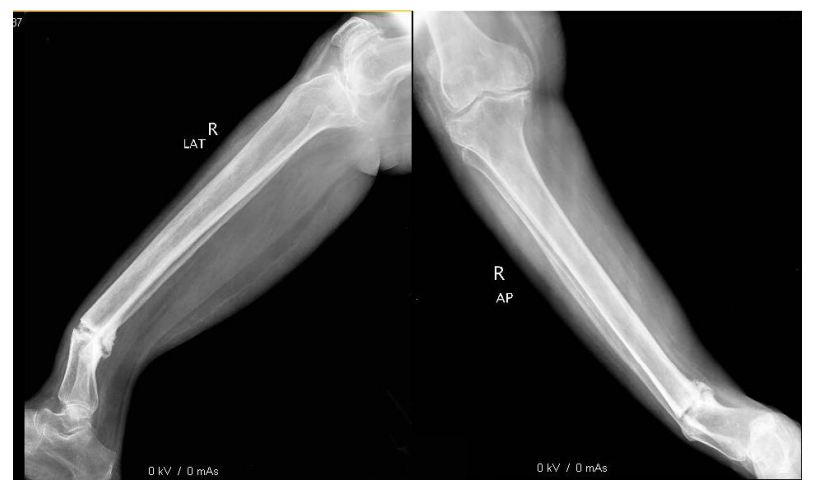

Figure 2. Stress fracture distal tibia with angulation and deformity.

Patient underwent intramedullary interlocking nailing for tibia with autogenous bone grafting (Figure 3). Patient was kept non touchdown weight bearing for three months till the fracture union was achieved. The subsequent follow up X-rays at twelve weeks showed bony union (Figure 4). One year later patient underwent implant removal and bilateral total knee replacement.

\section{Discussion}

Repetitive cyclical loading of a bone due to micro trauma can cause stress fracture. The stress fracture can occur as a result of low intensity abnormal stresses in abnormal bone (fatigue fracture) or normal stress placed on an abnormal bone (insufficiency fracture) [10].

Common sites for the stress fracture reported in the literature are shaft of tibia, Metatarsal shaft, fibula, and femoral neck. Clinical features involve history of vague pain at the site and discomfort. On examination there is localized tenderness. The detection of a stress fracture may be difficult in the initial part, as the radiographs may be normal. Technetium bone scan can detect stress fracture with greater accuracy. The stress fracture is most common in tibia, accounting for $50 \%$ cases. The commonest site in the tibia is proximal third $[10,15]$. Various treatment options are cast immobilization, locked intramedullary nail; osteotomy and internal fixation with compression plate are described to achieve union in proximal tibial stress fractures. Modular total knee prosthesis with a long tibial stem extension has also been described as salvage for failed osteotomy and internal fixation for proximal tibial stress fracture. Modular total knee prosthesis helps to correct malalignment of the limb, stabilize the fracture and replacement of the arthritic joint. A modular TKR with a long extension of the tibial stem allows these objectives to be met and is a safe solution for this difficult problem $[11,12,14,16]$. Our patient had stress fractures of distal tibial shaft secondary to advanced osteoarthritis of knee with varus deformity. To the best of our knowledge we came across only one previous case

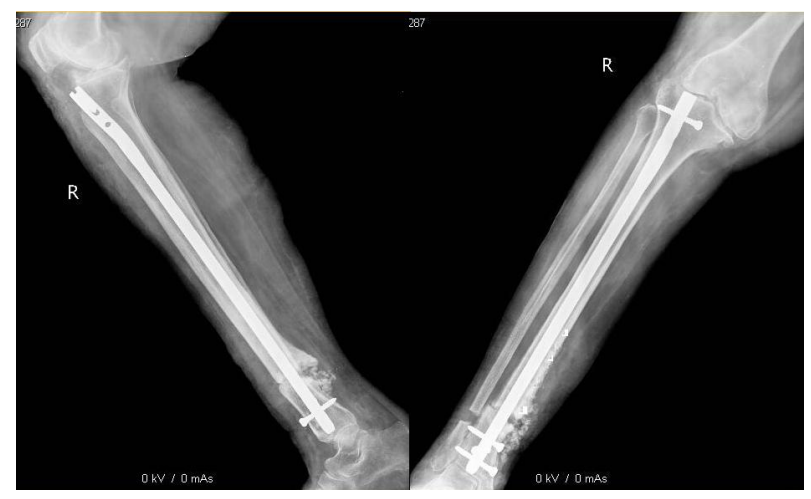

Figure 3. Poat op radiograph showing corrected deformity with implants and the graft in situ.

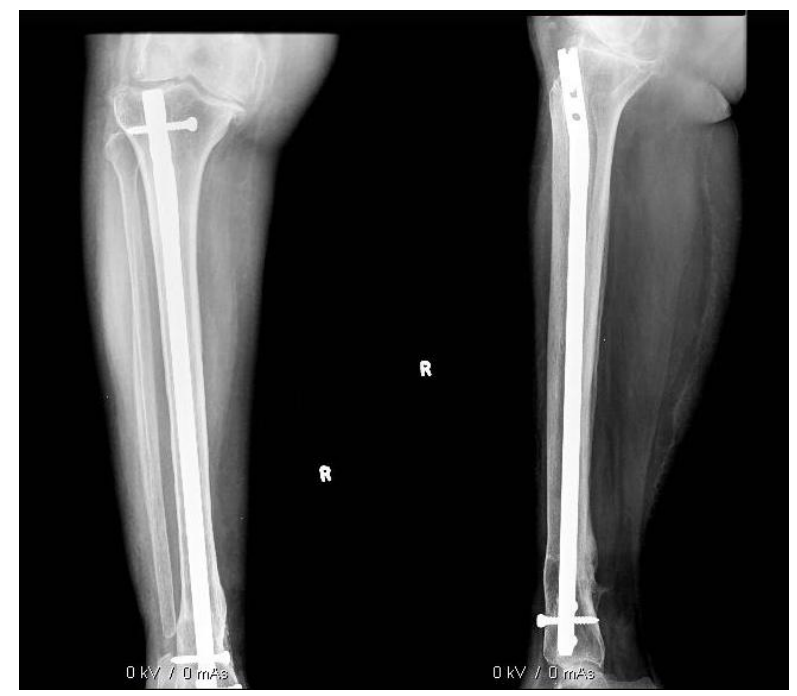

Figure 4. United fracture with well corrected defrmity with intramedullary interlocking nail in situ.

report involving the distal tibia [10]. As the fracture was in distal third with angular deformity modular knee prosthesis couldn't be used in our case. Risk factors for stress fracture are abnormal mechanical loading such as varus or Valgus deformity, limb length discrepancy and unaccustomed repetitive stress as occurs in military recruits. The mechanism of stress fracture is that deformity of the knee will produce abnormal loading of the tibia. The eccentric loading of a long bone sets up tension stresses on its convex side and compresses the concave aspect $[5,6,17]$.

We performed an open reduction, correction of the deformity and an intramedullary interlocking nailing with autogenous bone grafting in this patient. As there are continued stresses at the osteosynthesis site, due to persistent varus deformity at the knee, a load sharing device such as an intramedullary interlocking nailing was preferred in our case to a load bearing device such as a plate.

The distal tibial stress fractures secondary to severe 
varus deformity of osteoarthritic knee are to very common. Unlike the proximal tibial stress fractures in osteoarthritis, these cannot be treated with total knee arthroplasty with along tibial stem. Such stress fractures when detected need aggressive treatment and can be treated by an intramedullary interlocking nailing, which can resist the continued varus forces due to persistent varus knee deformity. These patients can undergo a total knee arthroplasty, once the union is achieved at the stress fracture site.

\section{REFERENCES}

[1] C. Milgrom, M. Giladi, M. Stein, H. Kashtan, J. Margulies, R. Chisin, R. Steinberg, A. Swiss and Z. Aharonson, "Medial Tibial Pain: A Prospective Study of Its Cause among Military Recruits," Clinical Orthopaedics, Vol. 213, 1986, pp. 167-171.

[2] M. Devas, "Stress Fractures," Churchill Livingstone, Edinburgh, 1975.

[3] M. Giladi, Z. Ahronson, M. Stein, Y. L. Danon and C. Milgram, "Unusual Distribution and Onset of Stress Fractures in Soldiers," Clinical Orthopaedics, Vol. 192, No. , 1985, pp. 142-145.

[4] D. J. Ross, P. A. Dieppe, I. Watt and J. H. Newman, "Tibial Stress Fracture in Pyrophosphate Arthropathy," Journal of Bone \& Joint Surgery (British), Vol. 65, No. 4, 1983, pp. 474-477.

[5] M. T. Reynolds, "Stress Fractures of the Tibia in the Elderly Associated with Knee Deformity," Journal of the Royal Society of Medicine, Vol. 65, No. 4, 1972, pp. 377380.

[6] F. Wheeldon, "Spontaneous Fractures in the Shin in the Presence of Knee Deformities," Journal of the Royal Society of Medicine, Vol. 54, 1961, p. 1108.

[7] A. Young, P. Kinsella and P. Boland, "Stress Fractures of the Lower Limb in Patients with Rheumatoid Arthritis," Journal of Bone \& Joint Surgery (British), Vol. 63-B, No. 2, 1981, pp. 239-243.

[8] K. Satku, V. P. Kumar and R. W. H. Pho, "Stress Fractures of the Tibia in Osteoarthritis of the Knee," Journal of Bone \& Joint Surgery (British), Vol. 69, No. 2, 1987, pp. 309-311.

[9] E. D. Nabors, T. E. Kremchek and D. W. Burke, "Stress Fracture of the Proximal Tibia Associated with Severe Osteoarthritis," American Journal of Knee Surgery, Vol. 8, 1995, pp. 141-143.

[10] I. K. Tey, K. W. Chong and I. Singh, "Stress Fracture of the Distal Tibia Secondary to Severe Knee Osteoarthritis: A Case Report," Journal of Orthopaedic Surgery, Vol. 14, No. 2, 2006, pp. 212-215.

[11] J. Kopacz, E. Warda and T. Mazurkiewicz, "Stress Fractures of the Tibia in Elderly Women [in Polish]," Chirurgia Narzadow Ruchu i Ortopedia Polska, Vol. 67, No. 5, 2002, pp. 515-520.

[12] M. H. Sy, S. Diouf, A. Ndoye and M. Coume, "A New Case of Tibial Stress Fracture as a Complication of Knee Osteoarthritis [in French]," Revue de Chirurgie Orthopedique et Reparatrice de l'Appareil Moteur, Vol. 81, No. 5, 1995, pp. 445-448.

[13] B. G. Seral, D. Palanca and F. Seral, "Stress Fracture of the Proximal Tibia Associated with Severe Osteoarthritis of the Knee. Case Report," American Journal of Knee Surgery, Vol. 10, No. 4, 1997, pp. 228-231.

[14] M. R. Sawant, S. P. Bendall, T. G. Kavanagh and N. D. Citron, "Nonunion of Tibial Stress Fractures in Patients with Deformed Arthritic Knees. Treatment Using Modular Total Knee Arthroplasty," Journal of Bone \& Joint Surgery (British), Vol. 81, No. 4, 1999, pp. 663-666. doi:10.1302/0301-620X.81B4.9091

[15] W. M. Chen, C. K. Huang, T. H. Chen, C. C. Chiang and W. H. Lo, "Bilateral Proximal Tibial Stress Fractures in Osteoarthritic Knee Treated with Simultaneous Corrective Osteotomy and Internal Fixation," Journal of the Chinese Medical Association, Vol. 67, No. 1, 2004, pp. 48-50.

[16] M. Haspl, M. Jelić and M. Pećina, "Arthroplasty in Treating Knee Osteoarthritis and Proximal Tibia Stress Fracture," Acta Chirurgiae Orthopaedicae et Traumatologiae Cechoslovaca, Vol. 70, No. 5, 2003, pp. 303-305.

[17] M. Alms, "Fracture Mechanics," Journal of Bone \& Joint Surgery (British), Vol. 43-B, 1961, pp. 162-166. 